\title{
Inhibitory effect of carbonyl reductase 1 on ovarian cancer growth via tumor necrosis factor receptor signaling
}

\author{
RIE MIURA, YOSHIHITO YOKOYAMA, TATSUHIKO SHIGETO, \\ MASAYUKI FUTAGAMI and HIDEKI MIZUNUMA \\ Department of Obstetrics and Gynecology, Hirosaki University \\ Graduate School of Medicine, Hirosaki, Aomori 036-8562, Japan
}

Received August 12, 2015; Accepted October 1, 2015

DOI: 10.3892/ijo.2015.3205

\begin{abstract}
We investigated the mechanisms of the inhibitory effect of carbonyl reductase 1 (CR1) on ovarian cancer growth mediated by the activation of the tumor necrotic factor receptor (TNFR) pathway. OVCAR-3 and TOV21G cells overexpressing CR1 were constructed by transfecting them with CR1 cDNA by lipofection. CR1-overexpressing and control OVCAR-3 and TOV21G cells were injected subcutaneously into nude mice and the tumor growth was compared between the two groups for 3-4 weeks. The expression of TNFR1 and TNFR2 in tumors was examined immunohistochemically at the end of the experiment. Expression levels of caspase- 8 and -3 activated by TNFR1, c-Jun activated by TNFR2, and $\mathrm{NF}-\kappa \mathrm{B}$ activated by both TNFR1 and TNFR2 were determined using immunohistochemistry and western blot analysis. Tumor growth was significantly suppressed in mice injected with CR1-overexpressing cells. Tumor volume in the CR1 induction group decreased temporarily until 2 weeks. Tumor cell membranes in both CR1 induction and control groups were positive for TNFR1 expression; however, total protein levels did not differ between the two groups. TNFR-2 expression was comparatively weak in both groups. The expression of NF- $\kappa \mathrm{B}$ and c-Jun was weaker in the CR1 induction group than in control. In contrast, caspase- 8 and -3 expression was higher in the CR1 induction group. Furthermore, the number of apoptotic cells was significantly greater in tumors that appeared after injections of both types of CR1-overexpressing cells than in those of control cancer cells. These results suggest that $\mathrm{CR} 1$ induces apoptosis by activating the caspase pathway via binding to TNFR1.
\end{abstract}

Correspondence to: Dr Yoshihito Yokoyama, Department of Obstetrics and Gynecology, Hirosaki University Graduate School of Medicine, 5-Zaifu-cho, Hirosaki, Aomori 036-8562, Japan

E-mail: yokoyama@hirosaki-u.ac.jp

Key words: carbonyl reductase 1, ovarian cancer, tumor necrotic factor receptor 1, caspases, apoptosis, NF- $\kappa \mathrm{B}$

\section{Introduction}

Ovarian cancer is the seventh most common cancer in women under the age of 65 years. Epithelial ovarian cancer (EOC) constitutes the majority of ovarian neoplasms (1). It is often not detected until the advanced stages and is the most frequent cause of death among gynecologic cancers (2). Over the last several years, the treatment of ovarian cancer has not appreciably changed. Cytoreductive surgery followed by adjuvant chemotherapy is generally recommended as the primary treatment for advanced EOC. Over $70 \%$ of patients respond to chemotherapy initially, but $\sim 50 \%$ of advanced cases will relapse (3). Many drugs have been developed so far to treat EOC; however, the improvement in the prognosis of EOC patients is insufficient. Therefore, new clinically useful biomarkers and new targets for EOC treatment need to be identified.

Clofibric acid (CA), a peroxisome proliferator-activated receptor $\alpha$ (PPAR $\alpha$ ) ligand, which is commonly used for the treatment of hyperlipidemia, may be one of the possible EOC treatments. Our previous in vivo and in vitro studies have demonstrated that CA has an antitumor effect against human ovarian cancer, which is comparable to that of cisplatin (4). We have previously shown that CA treatment induces the expression of carbonyl reductase 1 (CR1), which in turn decreased prostaglandin (PG) $\mathrm{E}_{2}$ levels; the treatment also causes significant induction of apoptosis and profound repression of angiogenesis (4). CR1 is a NADPH-dependent oxidoreductase with a broad specificity for carbonyl compounds, which reduces aldehydes and ketones (5). CR1 is present in a variety of organs, such as the liver, kidney, breast, ovary, and vascular endothelial cells, and its primary function is considered to control fatty acid metabolism (6). Earlier reports have shown that there is a negative relationship between CR1 expression levels and malignant tumor growth (7-10). In order to elucidate antitumor effect of CR1, we transfected mouse ovarian cancer cells with a CR1 cDNA expression vector and investigated the effect of overexpressed CR1 on tumor growth in vivo, and found that tumor growth was significantly inhibited in mice from the CR1 induction group compared to tumor development in animals injected with intact, unmodified cell lines 
(11). Furthermore, the milk fat globule EGF factor 8 (MFGE8), an 'eat-me signal' for phagocytes such as macrophages, was expressed extensively in the cytoplasm of tumor cells and interstitial cells of mice from the CR1 induction group. MFG-E8 is released by apoptotic endothelial cells and induces engulfment of apoptotic cells by macrophage (12). Activated macrophages are the major source of tumor necrosis factor $\alpha$ $(\mathrm{TNF} \alpha)$ and TNF $\alpha$ is a key cytokine involved in inflammation, cellular homeostasis, tumor progression and carcinogenesis (13).

Therefore, we focused on TNF $\alpha$, a potent cytokine, which is produced by many types of cells, including macrophages. $\mathrm{TNF} \alpha$ elicits a particularly broad spectrum of whole body and cellular responses, including activation and migration of immune cells, fever, acute phase response, cell proliferation, differentiation, and apoptosis (14). TNF $\alpha$ exerts its effects through two distinct receptors, TNF receptor 1 (TNFR1) and TNFR2 (15). Binding of the inherently trimeric TNFa to TNFR1 and TNFR2 induces receptor trimerization and recruitment of several signaling proteins to the cytoplasmic domains of the receptor (15). TNFR1 transduces apoptotic and anti-inflammatory signals through the recruitment of the Fas-associated death domain protein (FADD) and subsequent recruitment of caspase-8 $(16,17)$. Thereafter, activated caspase-8 initiates a proteolytic cascade that involves other caspases (caspase-3,-6 and -7) and ultimately induces apoptosis $(16,17)$. TNFR1 also mediates anti-apoptotic and inflammatory responses such as the induction of necrosis factor $(\mathrm{NF})-\mathrm{KB}$ through the recruitment of TNF-receptor-associated factor 2 (TRAF2) and receptor-interacting protein 1 (RIP1) $(18,19)$. On the other hand, TNFR2 recruits TRAF2 and TRAF1 to transmit anti-apoptotic and inflammatory signals inducing the expression of NF- $\mathrm{KB}$ and c-Jun (20).

In this study, we investigated the mechanism of antitumor effects of CR1 mediated by TNFR1 and TNFR2 signaling.

\section{Materials and methods}

Cell lines and cell culture. OVCAR-3 and TOV-21G cell lines were obtained from the American Type Culture Collection (Rockville, MD, USA). Both OVCAR-3 and TOV-21G cells are derived from human ovarian cancer tissues and are commonly used to produce xenografted solid tumors (10,21-23). The cells were cultured in the RPMI-1640 medium supplemented with $10 \%$ fetal calf serum (FCS), $100 \mathrm{U} / \mathrm{ml}$ penicillin, and $100 \mathrm{mg} / \mathrm{ml}$ streptomycin at $37^{\circ} \mathrm{C}$ in a humidified air containing $5 \% \mathrm{CO}_{2}$.

Animal experiments. Animal experiments were conducted in accordance with the Guidelines for Animal Experimentation of Hirosaki University. Eight-week-old female BALB/c nu/nu mice were used in this study. All mice were group housed in plastic cages with stainless-steel grid tops in an air-conditioned room at the Institute for Animal Experiments of Hirosaki University. Mice were kept on a 12/12-h light/dark cycle and given ad libitum access to food and water.

Plasmid DNA preparation. To achieve highly efficient transfection, we used the pCMV6-AC-GFP vector (OriGene Technologies, Rockville, MD, USA) that encodes human CR1, the green fluorescent protein (GFP), and the ampicillin-resistant gene. For amplification, pCMV6-AC-GFP was transformed into E. coli $\mathrm{DH} 5 \alpha$ competent cells by heat shock transformation according to standard laboratory protocols. The transformed bacteria were amplified in LB-ampicillin medium. The plasmids were purified from cultured-transformed bacteria using Maxiprep PureLink HiPure Plasmid Filter DNA Purification kits (Invitrogen, Carlsbad, CA, USA) according to the manufacturer's protocol. Plasmid DNA (pDNA) was diluted in sterile water to a concentration of $2 \mu \mathrm{g} / \mu \mathrm{l}$.

Transfection. OVCAR-3 and TOV-21G cells were plated into $10-\mathrm{cm}$ well plates and cultured to $70-80 \%$ confluence in the RPMI-1640 medium supplemented with $10 \%$ fetal calf serum (FCS). Then, $24 \mu \mathrm{g}$ of the coding plasmid was transfected into OVCAR-3 and TOV-21G cells using Lipofectamine (Life Technologies, Rockville, MD, USA) according to the manufacturer's protocol. The vector without CR1 pDNA was used as control. Transfected cells were cultured in the RPMI-1640 medium supplemented with $10 \%$ fetal calf serum (FCS) for $48 \mathrm{~h}$. We confirmed the expression of the CR construct using fluorescence microscopy.

Xenograftmouse model. The mice were divided into two groups ( $\mathrm{n}=5$ for each group) for each of the two types of cancer cells used. Normal OVCAR-3 cells or OVCAR-3 overexpressing the CR1-DNA (5.0x10 $0^{6}$ cells) were injected subcutaneously in $0.2 \mathrm{ml}$ of RPMI-1640 medium into the back region of nude mice. All mice were numbered, housed separately, and tumor development was examined by measuring 2 diameters twice a week using a caliper. Tumor dimensions were measured twice a week using a caliper. Tumor volume was calculated using the following equation: $\mathrm{V}\left(\mathrm{mm}^{3}\right)=\mathrm{A} \times \mathrm{B} 2 / 2$, where $\mathrm{A}$ is the largest diameter and B is the smallest diameter (10). On the third or fourth week of the experiment, animals were sacrificed and tumors were isolated for pathological and biochemical examinations.

Immunohistochemistry. Six-micrometer-thick sections of formalin-fixed and paraffin-embedded tissue specimens were stained by an established method, as described previously (4). Sections were incubated with antibodies specific for TNFR1, TNFR2, caspase-8, caspase-3, NF- $\mathrm{kB}$, and c-Jun (Santa Cruz Biotechnology, Santa Cruz, CA, USA) overnight at $4^{\circ} \mathrm{C}$. Slides were incubated with appropriate biotinylated speciesspecific secondary antibodies for $1 \mathrm{~h}$ and then exposed to avidin-biotin-peroxidase complex. Sections were treated with $0.02 \%$ diaminobenzidine as a chromogen and counterstained with hematoxylin.

Western blot analysis. Cell lysates ( $25 \mu \mathrm{g}$ protein) were prepared from tumor tissues, electrophoresed using a $12 \%$ precast polyacrylamide gel onto nitrocellulose membranes (Bio-Rad Laboratories). The protein concentration was determined using the Bradford assay. The blots were probed for $2 \mathrm{~h}$ with the diluted antibodies against the following proteins: CR1 (Santa Cruz Biotechnology) at 1:500, human caspase-8 (Santa Cruz Biotechnology) at 1:200, caspase-3 (Santa Cruz Biotechnology) at 1:200, NF-кB (Santa Cruz Biotechnology) at 1:500, c-jun (Santa Cruz Biotechnology) at 1:500, and 
A

OVCAR-3

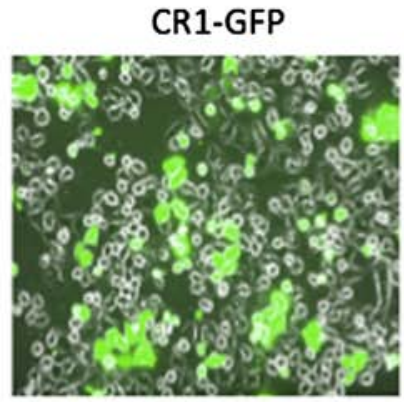

TOV-21G
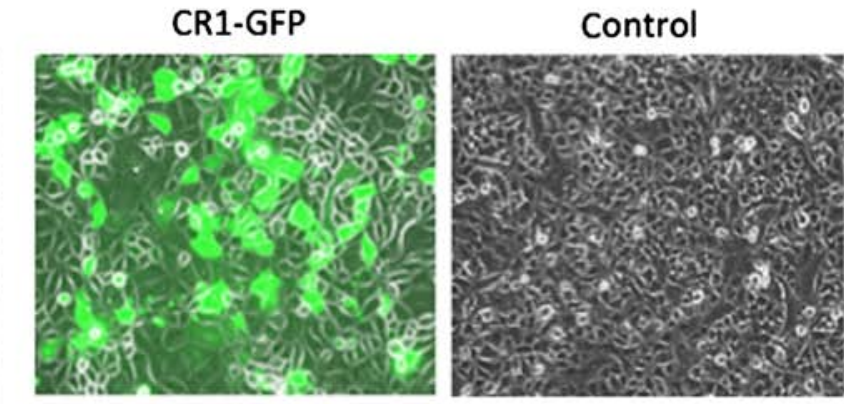

B

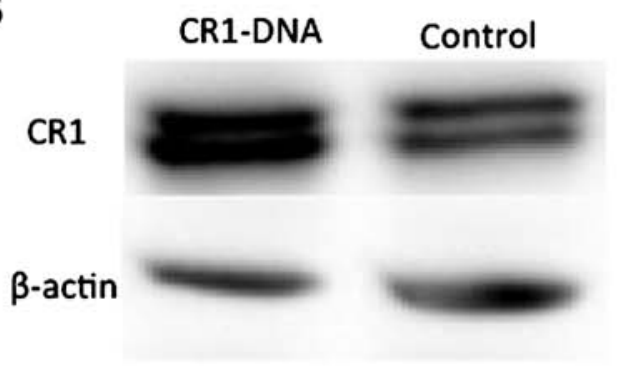

Control

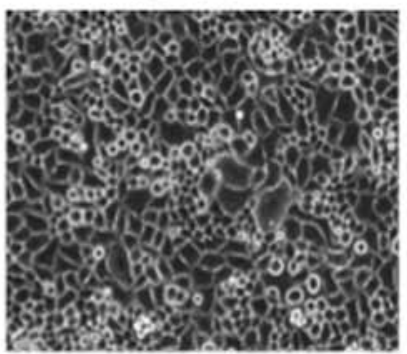

列


A

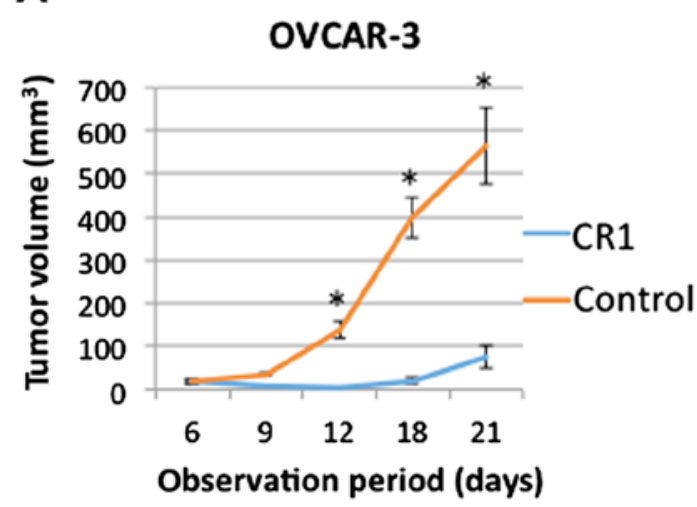

B

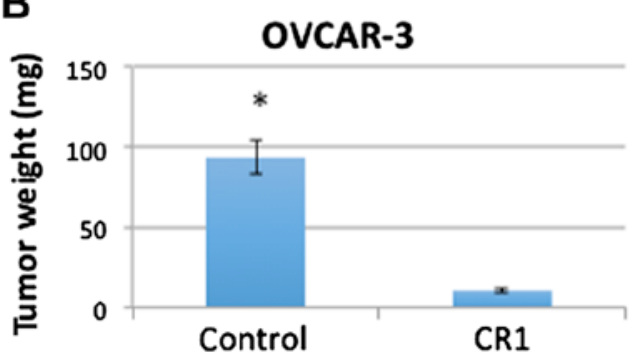

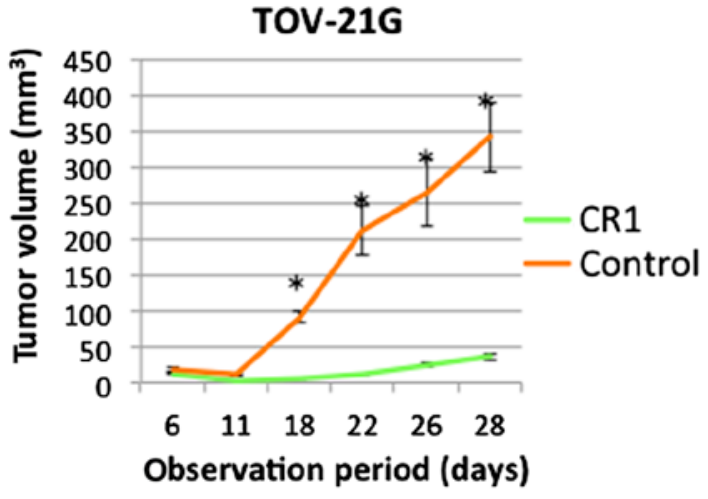

TOV-21G

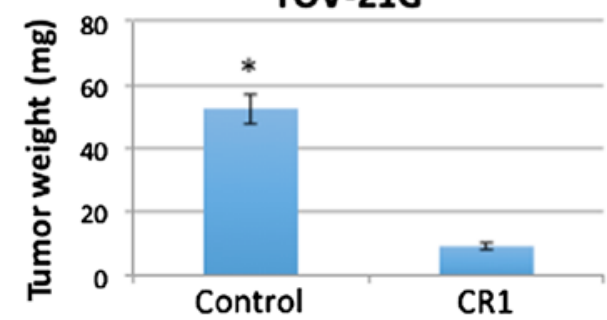

Figure 2. Comparison of tumor growth in a xenograft mouse model. (A) Tumor growth of OVCAR-3 and TOV-21G cells. Tumor volume of OVCAR-3 was significantly lower in the CR1 induction group than in the control group after the 8th day of the experiment. Tumor volume of TOV-21G was significantly lower in the CR1 induction group than in the control group after 15th day of the experiment. (B) Tumor weight at the end of experiment. Tumor weight of CR1 induction group was significantly lighter than control group in both cell types. ${ }^{\mathrm{P}}<0.001$ versus the control.
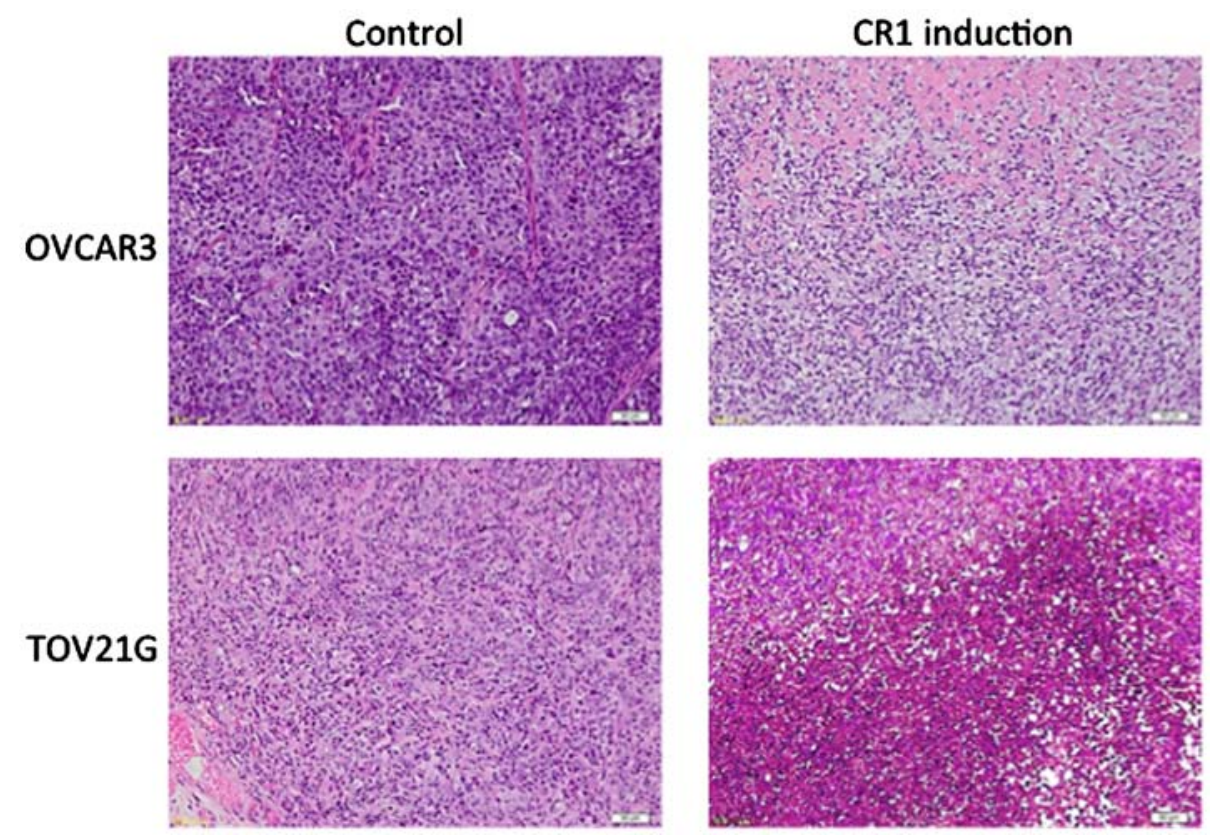

Figure 3. Hematoxylin-eosin staining of tumor tissues. Necrosis with inflammatory cells was observed in large areas of tumors in CR1 induction group. Magnification, x200.

anti-caspase- 8 antibody (24) was $112.0 \pm 19.5$ and $77.2 \pm 12.8$ in tumors caused by CR1-overexpressing OVCAR-3 and TOV-21G cells, respectively. Tumors induced by the injection of control OVCAR-3 and TOV-21G cells exhibited fewer apoptotic cells per $\mathrm{mm}^{2}$, that is, $18.0 \pm 7.7$ and $17.6 \pm 1.8$, respectively.
The differences between control and CR1 induction groups were statistically significant (Fig. 6, $\mathrm{P}<0.001$ each).

Effect of CR1-transfection on NF- $\kappa B$ and c-Jun expression. Western blot analysis showed that both NF- $\mathrm{BB}$ and 


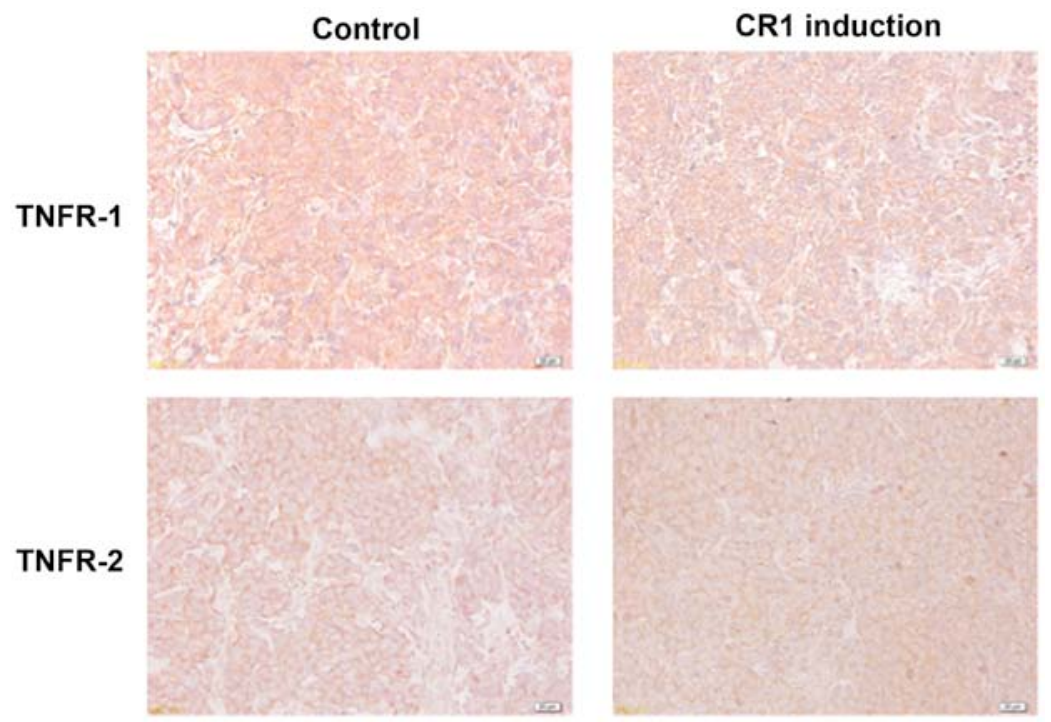

Figure 4. TNFR1 and TNFR2 were distributed in cell membranes of tumors from all treatment groups and there were no significant differences in their expression levels between CR1 induction and control groups. TNFR2 expression levels were comparatively weak in both groups. Magnification, x200.

A
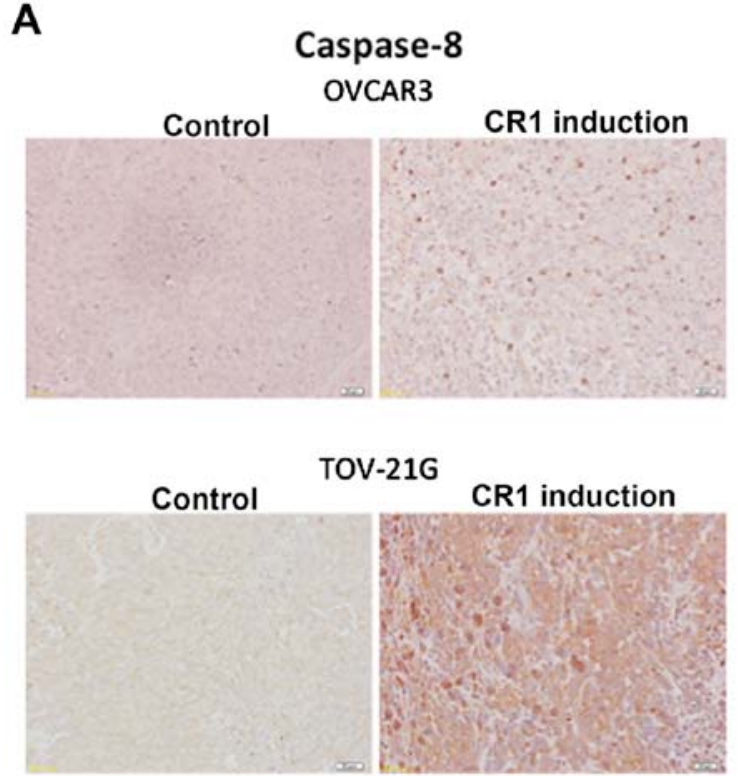

B

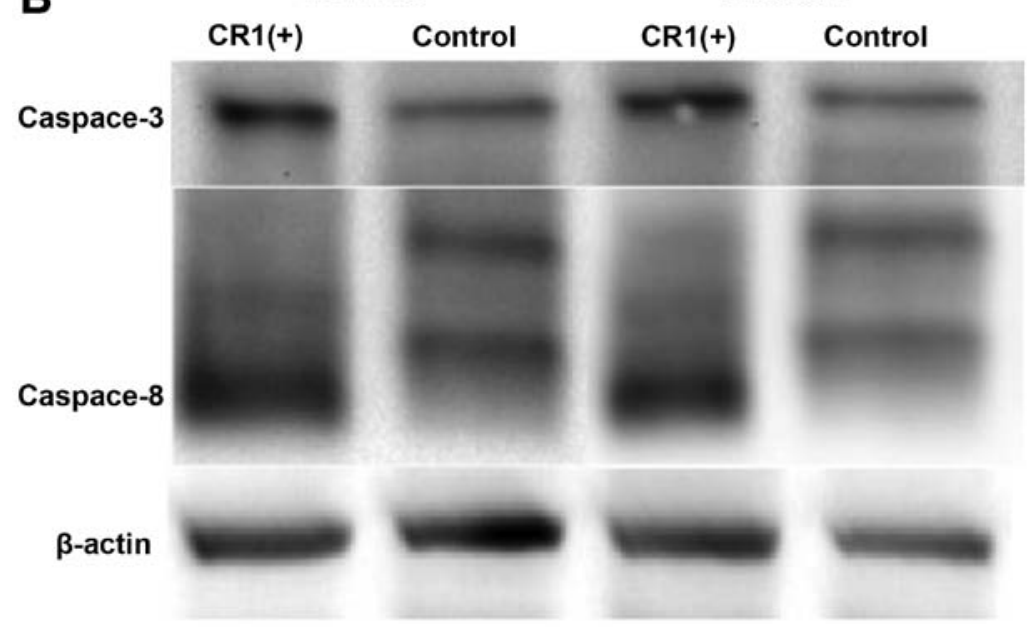

Figure 5. Caspase- 8 and -3 expression levels in tumors. (A) Immunohistochemistry showed that both caspase- 8 and -3 expression levels were higher in tumors caused by CR1-overexpressing OVCAR-3 and TOV-21G cells compared to their expression in tumors induced by control cell lines. Magnification, $\mathrm{x} 200$. (B) Western blot analysis showed the same result as immunohistochemistry. 
A

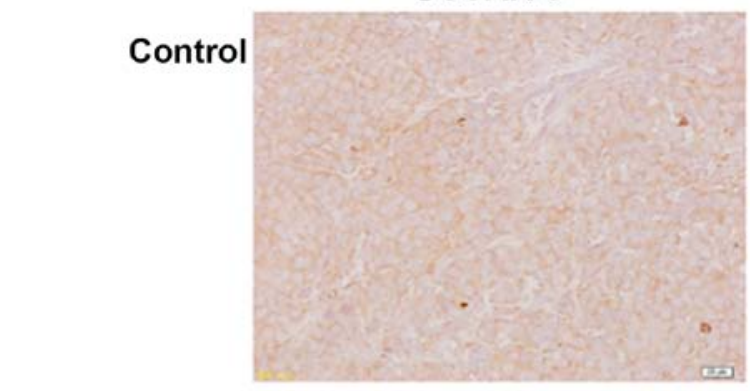

\section{CR1-induction}

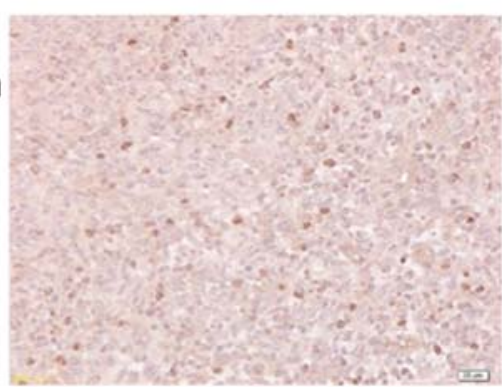

B

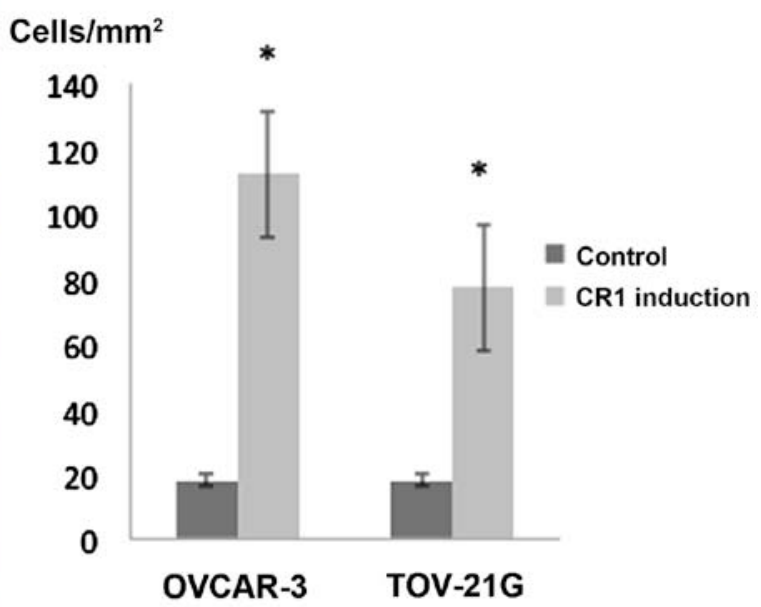

Figure 6. Apoptotic cells identified with an anti-caspase-8 antibody in tumors caused by CR1-overexpressing OVCAR-3 and TOV-21D and control tumors. (A) Brown-colored cells are apoptotic cells identified with caspase-8 antibody. Magnification, x200. (B) The number of apoptotic cells was significantly greater in CR1-overexpressing group than in control tumors. ${ }^{*} \mathrm{P}<0.0001$ versus the control.

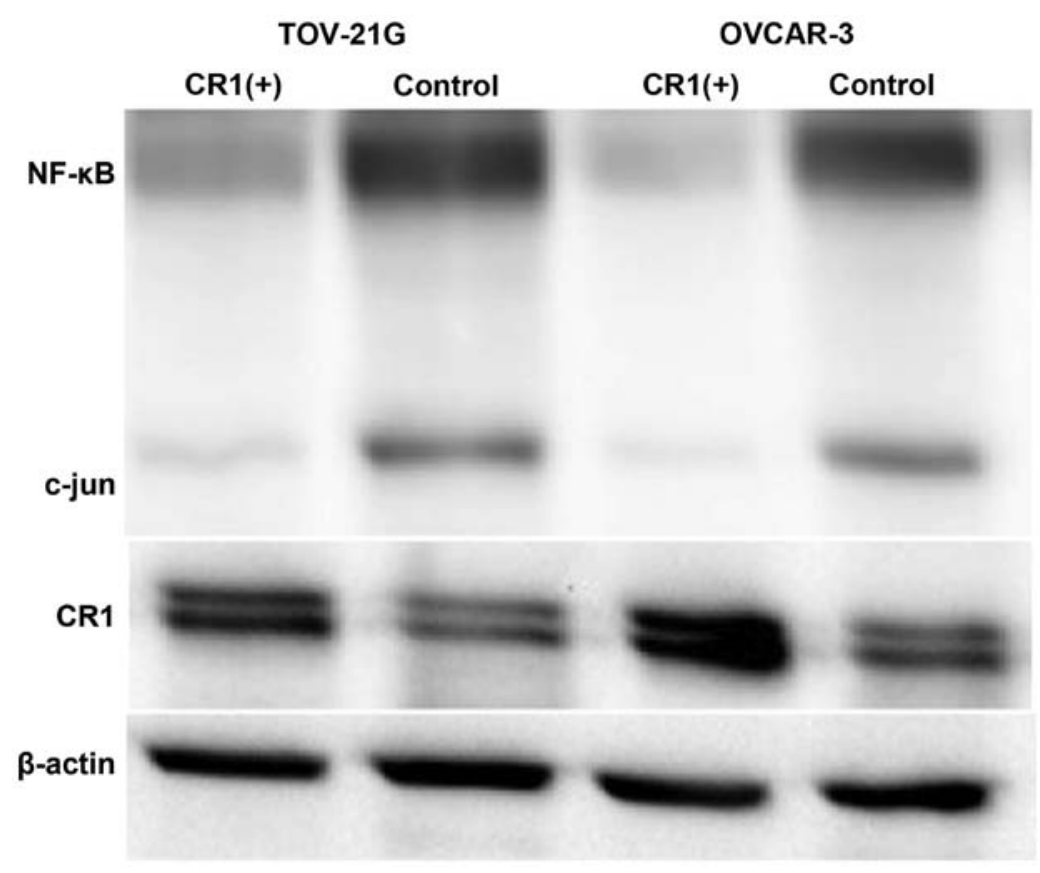

Figure 7. NF- $\mathrm{BB}$ and c-jun expression levels in tumors. Western blot analysis showed that both NF- $\mathrm{kB}$ and c-Jun expression levels were lower in tumors caused by CR1-overexpressing OVCAR-3 and TOV-21G cells compared to their expression in tumors induced by control cell lines.

c-Jun expression levels were lower in tumors caused by CR1-overexpressing OVCAR-3 and TOV-21G cells compared to their expression in tumors induced by control cell lines (Fig. 7).

\section{Discussion}

The results of this study show that subcutaneous injections of CR1-overexpressing OVCAR-3 and TOV-21G cells into the back region of nude mice formed smaller tumors in volume than injection with normal OVCAR-3 and TOV-21G cell lines and were compatible with our previous studies that showed spontaneous regression of malignant ovarian tumors with high expression of CR1 (11) and growth promotion of ovarian cancer cell lines by CR1 suppression (10). Because an increased expression of MFG-E8 in macrophages was also observed in our previous study (11), we speculated apoptosis as a putative mechanism of CR1 function. As shown in Fig. 5, we found that 
expression levels of caspase- 8 and -3 were higher in tumors with CR1 overexpressed cell lines, confirming our hypothesis. In addition, expression levels of NF- $\kappa \mathrm{B}$ and c-Jun were negatively affected in tumors with CR1 overexpression. $\mathrm{NF}-\kappa \mathrm{B}$ and c-Jun are known to cooperate to prevent apoptosis induced by $\mathrm{TNF} \alpha$, therefore we were interested to study TNFRs for TNF $\alpha$ with CR1.

TNFR1 is ubiquitously expressed in most tissues, whereas TNFR2 is mainly expressed in immune cells (13). Although both receptors bind $\mathrm{TNF} \alpha$, cellular effects of $\mathrm{TNF} \alpha$ in most cell types are predominantly mediated by TNFR1 (25). TNFR1 is an important member of the death receptor family and is capable of inducing apoptotic cell death (26). TNFR2 can also mediate cell death signals, which may be indirectly communicated through TNFR1 (26). As shown in Fig. 4, TNFR1 was expressed to equal levels regardless of CR1 expression, while TNFR2 was expressed weaker in both groups, suggesting that TNFR1 signaling has a more important role in tumor development. In order that TNFR1 elicits physiological function, it trimerizes and releases the silencer of death domain protein, which recruits adaptor proteins such as RIP, TRAF-2, and FADD (15). FADD binds to procaspase- 8 and activated caspase- 8 subsequently initiates a proteolytic cascade that involves other caspases (caspase-3, -6 and -7$)$ and ultimately induces apoptosis $(16,27)$. As shown in Fig. 5, because expression levels of caspase- 8 and -3 were higher in CR1 overexpressing tumors, it is presumed that CR1 induced apoptosis through the activation of caspase pathway. In addition, expression of $\mathrm{NF}-\kappa \mathrm{B}$ and $\mathrm{c}$-Jun was lower in $\mathrm{CR} 1-$ overexpressing tumors. NF- $\kappa \mathrm{B}$ and $\mathrm{c}-\mathrm{Jun}$ have been shown to induce transcription of genes related to proliferation and anti-apoptosis (13). Therefore, apoptosis induced by CR-1 overexpression can be accounted for by reduced expression of $\mathrm{NF}-\kappa \mathrm{B}$ and c-Jun. These results were compatible with earlier reports that showed an inhibitory effect of $N F-\kappa B$ on ovarian cancer growth $(28,29)$.

In conclusion, the results of this study show that CR1 has anticancer effects by inducing apoptosis through the TNF $\alpha$ system. Of interest, CR1 induced apoptosis of TOV-21G cell lines which are derived from chemo-resistant ovarian clear cell adenocarcinoma (30). Clear cell carcinoma is one of the most frequent of ovarian cancers and has poor prognosis (30), then the results of present study suggests that CR1 might become a new candidate for treatment of clear cell carcinoma. Further studies are required for clinical application of a PPAR $\alpha$ ligand or CR1 gene therapy.

\section{Acknowledgements}

This study was supported by a Grant-in Aid for Cancer Research from the Ministry of Education, Science and Culture of Japan (no. 20591935 to Y. Yokoyama).

\section{References}

1. Siegel R, Naishadham D and Jemal A: Cancer statistics, 2013 CA Cancer J Clin 63: 11-30, 2013.

2. Heintz AP, Odicino F, Maisonneuve P, Quinn MA, Benedet JL, Creasman WT, Ngan HY, Pecorelli S and Beller U: Carcinoma of the ovary. FIGO 26th Annual Report on the Results of Treatment in Gynecological Cancer. Int J Gynaecol Obstet 95 (Suppl 1): S161-S192, 2006.
3. McGuire WP, Hoskins WJ, Brady MF, Kucera PR, Partridge EE, Look KY, Clarke-Pearson DL and Davidson M: Cyclophosphamide and cisplatin compared with paclitaxel and cisplatin in patients with stage III and stage IV ovarian cancer. $\mathrm{N}$ Engl J Med 334: 1-6, 1996.

4. Yokoyama Y, Xin B, Shigeto T, Umemoto M, Kasai-Sakamoto A, Futagami M, Tsuchida S, Al-Mulla F and Mizunuma H: Clofibric acid, a peroxisome proliferator-activated receptor $\alpha$ ligand, inhibits growth of human ovarian cancer. Mol Cancer Ther 6: 1379-1386, 2007.

5. Gonzalez-Covarrubias V, Ghosh D, Lakhman SS, Pendyala L and Blanco JG: A functional genetic polymorphism on human carbonyl reductase 1 (CBR1 V88I) impacts on catalytic activity and NADPH binding affinity. Drug Metab Dispos 35: 973-980, 2007.

6. Wermuth B, Bohren KM, Heinemann G, von Wartburg JP and Gabbay KH: Human carbonyl reductase. Nucleotide sequence analysis of a cDNA and amino acid sequence of the encoded protein. J Biol Chem 263: 16185-16188, 1988.

7. Umemoto M, Yokoyama Y, Sato S, Tsuchida S, Al-Mulla F and Saito Y: Carbonyl reductase as a significant predictor of survival and lymph node metastasis in epithelial ovarian cancer. Br J Cancer 85: 1032-1036, 2001.

8. Murakami A, Fukushima C, Yoshidomi K, Sueoka K, Nawata S, Yokoyama Y, Tsuchida S, Ismail E, Al-Mulla F and Sugino N: Suppression of carbonyl reductase expression enhances malignant behaviour in uterine cervical squamous cell carcinoma: Carbonyl reductase predicts prognosis and lymph node metastasis. Cancer Lett 311: 77-84, 2011.

9. Murakami A, Yakabe K, Yoshidomi K, Sueoka K, Nawata S, Yokoyama Y, Tsuchida S, Al-Mulla F and Sugino N: Decreased carbonyl reductase 1 expression promotes malignant behaviours by induction of epithelial mesenchymal transition and its clinical significance. Cancer Lett 323: 69-76, 2012.

10. Osawa Y, Yokoyama Y, Shigeto T, Futagami M and Mizunuma H: Decreased expression of carbonyl reductase 1 promotes ovarian cancer growth and proliferation. Int J Oncol 46: 1252-1258, 2015.

11. Wang H, Yokoyama Y, Tsuchida S and Mizunuma H: Malignant ovarian tumors with induced expression of carbonyl reductase show spontaneous regression. Clin Med Insights Oncol 6: 107-115, 2012.

12. Hanayama R, Tanaka M, Miwa K, Shinohara A, Iwamatsu A and Nagata S: Identification of a factor that links apoptotic cells to phagocytes. Nature 417: 182-187, 2002.

13. van Horssen R, Ten Hagen TL and Eggermont AM: TNF-alpha in cancer treatment: Molecular insights, antitumor effects, and clinical utility. Oncologist 11: 397-408, 2006.

14. Tracey KJ and Cerami A: Tumor necrosis factor, other cytokines and disease. Annu Rev Cell Biol 9: 317-343, 1993.

15. Vandenabeele P, Declercq W, Beyaert R and Fiers W: Two tumour necrosis factor receptors: Structure and function. Trends Cell Biol 5: 392-399, 1995.

16. Rath PC and Aggarwal BB: TNF-induced signaling in apoptosis. J Clin Immunol 19: 350-364, 1999.

17. Degterev A, Boyce M and Yuan J: A decade of caspases. Oncogene 22: 8543-8567, 2003.

18. Barnes PJ and Karin M: Nuclear factor-kappaB: A pivotal transcription factor in chronic inflammatory diseases. N Engl J Med 336: 1066-1071, 1997.

19. Karin M, Liu Z and Zandi E: AP-1 function and regulation. Curr Opin Cell Biol 9: 240-246, 1997.

20. Rothe M,Pan M-G, Henzel WJ, Ayres TM and Goeddel DV: The TNFR2-TRAF signaling complex contains two novel proteins related to baculoviral inhibitor of apoptosis proteins. Cell 83: 1243-1252, 1995.

21. Shigeto T, Yokoyama Y, Xin B and Mizunuma H: Peroxisome proliferator-activated receptor $\alpha$ and $\gamma$ ligands inhibit the growth of human ovarian cancer. Oncol Rep 18: 833-840, 2007.

22. Wakui M, Yokoyama Y, Wang H, Shigeto T, Futagami M and Mizunuma H: Efficacy of a methyl ester of 5-aminolevulinic acid in photodynamic therapy for ovarian cancers. J Cancer Res Clin Oncol 136: 1143-1150, 2010.

23. Cebulla J, Huuse EM, Pettersen K, van der Veen A, Kim E, Andersen S, Prestvik WS, Bofin AM, Pathak AP, Bjørkøy G, et al: MRI reveals the in vivo cellular and vascular response to BEZ235 in ovarian cancer xenografts with different PI3-kinase pathway activity. Br J Cancer 112: 504-513, 2015.

24. Hirakawa H, Yokoyama Y, Yoshida $\mathrm{H}$ and Mizunuma $\mathrm{H}$ : Inhibitory effects of aromatase inhibitor on estrogen receptoralpha positive ovarian cancer in mice. J Ovarian Res 7: 4, 2014. 
25. McFarlane SM, Pashmi G, Connell MC, Littlejohn AF, Tucker SJ, Vandenabeele P and MacEwan DJ: Differential activation of nuclear factor-kappaB by tumour necrosis factor receptor subtypes. TNFR1 predominates whereas TNFR2 activates transcription poorly. FEBS Lett 515: 119-126, 2002.

26. Wajant H, Pfizenmaier K and Scheurich P: Tumor necrosis factor signaling. Cell Death Differ 10: 45-65, 2003.

27. Naudé PJ, den Boer JA, Luiten PG and Eisel UL: Tumor necrosis factor receptor cross-talk. FEBS J 278: 888-898, 2011

28. Zerbini LF, Tamura RE, Correa RG, Czibere A, Cordeiro J, Bhasin M, Simabuco FM, Wang Y, Gu X, Li L, et al: Combinatorial effect of non-steroidal anti-inflammatory drugs and NF- $\mathrm{BB}$ inhibitors in ovarian cancer therapy. PLoS One 6 : e24285, 2011.
29. Nishio H, Yaguchi T, Sugiyama J, Sumimoto H, Umezawa K, Iwata T, Susumu N, Fujii T, Kawamura N, Kobayashi A, et al: Immunosuppression through constitutively activated $N F-\kappa B$ signalling in human ovarian cancer and its reversal by an NF- $\kappa B$ inhibitor. Br J Cancer 110: 2965-2974, 2014.

30. Takano M, Sugiyama T, Yaegashi N, Sagae S, Kuzuya K, Udagawa Y, Tsuda H, Suzuki M, Kigawa J, Goto T, et al: Less impact of adjuvant chemotherapy for stage I clear cell carcinoma of the ovary: A retrospective Japan Clear Cell Carcinoma Study. Int J Gynecol Cancer 20: 1506-1510, 2010. 